\title{
PRESENTACIÓN
}

Carlos de la Isla*

\section{De la perplejidad a la utopía}

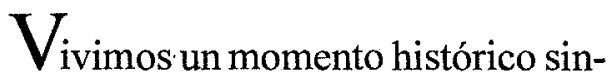
gular. En México, en el mundo se percibe un estado de incertidumbre y perplejidad. Parece que todo apunta hacia la necesidad de cambiar profundamente el presente y de inventar el futuro.

Tal vez la expresión central del malestar consiste en que esa especial mercancía de la que Marx hablaba se ha devaluado aún más: "sube el precio de las cosas, baja el precio de los hombres" (Ernesto Cardenal) y además de enajenado el hombre contemporáneo se ha quedado agredido, solo y ciego. Es bella, terrible y realista la descripción que hace Eduardo Milán de esa ceguera y de esa soledad: "El individuo ya no es perseguido como el héroe trágico; es excluido de un orden ... el orden ya no quiere aleccionar ni siquiera por capricho como en la mitología griega; requiere seguimiento, silencio, aceptación. Ya no estamos frente al dispositivo disparado por el héroe en Edipo Rey. Estamos con Edipo solo, viejo en Colono, sostenido a la izquierda por un bastón de madera, a la derecha por la mano de su hija Antígona, y por si fuera poco, ciego." Y en un poema que inicia: "Esto no puede seguir asi", subraya: "El sujeto está omitido, matado, metido a muerto." Percepción muy semejante a la de Erich Frömm cuando realiza su "Psicoanálisis de la sociedad contemporánea" y concluye: así como el grito predominante

* Instituto Tecnológico Autónomo de México. 
del siglo XIX fue "Dios ha muerto" así el del siglo XX es "el hombre ha muerto".

Por supuesto que esta muerte como fuerte metáfora quiere describir al hombre caprichosamente manejado, jaloneado por todos los hilos de todos los poderes, convirtiendo la "historia en el gran juego de las marionetas", marionetas sin conciencia de identidad, sin conciencia de su quehacer ni de su propia existencia, que queda atrapada entre la indiferencia del sueño, la sombra y la realidad. Bien lo expresa Becket con palabras que pone en boca de Malone: "nada importa que haya nacido o no, que haya vivido o no, que esté muerto o sólo agonizante. Seguiré haciendo lo que siempre he hecho en la ignorancia de lo que hago, de quién soy, de qué soy o de si acaso soy; pero tal vez sea el momento en que vivir es errar".

El hombre devaluado o muerto está allí en los más de tres mil millones de personas en el mundo que viven en situación infrahumana, situación vergonzosa frente a la enfermiza opulencia de pocos hombres y naciones, frente al derroche de armas, de ejércitos y de la ciencia ficción de la neurosis destructiva. Situación vergonzosa del hombre en el mundo que hace exclamar con voz patética a Boutros B. Ghali en la primera reunión internacional sobre desarrollo: "Es necesario un nuevo contrato social."

El precio del hombre a la baja está presente en esa fácil manera, violenta manera de acabar con la vida humana. Guerras en nombre de Dios, en nombre de la nación, en nombre de la libertad; guerras que usan a Dios, a la Nación, a la libertad para encubrir el único, el verdadero objetivo: el poder económico, el poder político, el placer de la dominación. "Esta Nación (decía Ronald Reagan con determinación frenética) está dispuesta a hacer todo lo que sea necesario para seguir siendo la nación más poderosa del mundo." Clásico ejemplo de las ideologías de poder y dominación que se convierten en locura perversa. Locura de poder que se interesa mucho más por la inversión en las armas y guerras galáxicas que por el hambre y la degradación del hombre en el mundo. "Baja el precio de los hombres." 


\section{PRESENTACIÓN}

La devaluación del hombre está presente en el libre mercado, que cuando se da entre desiguales genera las más ofensivas desigualdades; libertad de mercado que se transforma en libertad opresora de los débiles; está presente en la globalización (eufemismo del neocolonialismo) que, puesto en libertad el capital, se convierte en la estampida que arrolla por igual las culturas locales, los arraigos vitales, las soberanías y los cotos de todas las dimensiones; la globalización que termina sometiendo al mundo a la plataforma unidimensional del poder y del mercado vulgar e inhumano, que pone al alza el precio de las cosas y a la baja el precio de los hombres.

En este contexto son muy significativas y causales las corrientes filosóficas más influyentes: El humanismo racionalista, antropocéntrico, individualista hermanado con la concepción liberal que desde su dimensión de soberanía humana construye un hombre con libertades casi infinitas y poderes arbitrarios sobre la naturaleza y la sociedad: "En lo que a sí concierne cada individuo es soberano sobre sí mismo, su cuerpo y su espíritu" (J.S. Mill). El materialismo en concepciones y aspiraciones que limita al hombre al encierro de su tiempo y de su espacio y niega al "hombre que supera infinitamente al hombre" (Pascal). El subjetivismo relativista que por dar valor a todo por igual termina devaluando todo por igual en la igualación del nadismo.

Es especialmente significativa en el ámbito de estas concepciones la arbitraria condena de la razón en el juicio postmoderno de la modernidad, de la cual deriva la también arbitraria descalificación de los frutos de la razón que dan estabilidad, permanencia y firmeza al plano de la existencia.

Desacreditada la razón se genera la inestabilidad, el caos, el vacío, y la existencia se convierte en "el barco a la deriva, en la tempestad, sin faro, sin brújula, sin timonel" (Spengler).

Resultados inevitables: la soledad, la violencia invidente, el vacío. Isahiah Berlin, compañero de casi todo el siglo, exclama con decepción: "siglo cruel me ha tocado vivir"; Marguerite Yourcenar expresa así la soledad del hombre desposeído: "Cuando los dioses ya no existían hubo un momento único en el que el hombre estuvo solo"; soledad 
semejante a la de Edipo solo y ciego. Mientras que refiriéndose a ese mundo de violencia y soledad producido por la ausencia de verdades, bienes y valores o por su opuesto ideológico, el dogmatismo fundamentalista, Ionesco formula este simple diagnóstico: "Este mundo está pleno de vacío."

El diagnóstico del presente expresado por serios pensadores de este siglo genera un estado de intensa perplejidad, y desde esta perplejidad se abren dos caminos: el de la desesperación y el de la utopía. La perplejidad es asombro pero no sólo asombro; la perplejidad no es sólo desconcierto o rompimiento de la armonía del concierto del espíritu, pero también es desconcierto; la perplejidad es angustia, pero no "la angustia que se angustia de todo y de nada" (Heidegger), sino la angustia que produce la tensión de las disyuntivas; la perplejidad tiene algo de la duda, pero no permanece en el escepticismo de la indefinición, es más bien el resultado de esa "gota de duda que hay que dejar caer sobre lo que se dice" (O. Paz) para evitar el dogmatismo, que es menos aceptable que el escepticismo como actitud reflexiva; la perplejidad es un estado de tensión, y por supuesto que los problemas de nuestro mundo causan tensión; sin embargo esto no significa que el

10 perplejo viva en permanente tensión. "La permanencia de un estado de irresuelta perplejidad tendría bastante más de pesadilla y hasta de maldición que de dádiva o regalo de los cielos" (J. Muguerza). Por eso la perplejidad que no es permanente tensión, generada por la soledad, la violencia y el vacío, puede resolverse en la desesperación o en la utopía.

Ha sido muy frecuente la resolución desesperada de la perplejidad presente, porque el vacío es el suelo firme de la desesperación y de la locura. Es muy elocuente en este sentido el comentario que Octavi Marti, discípulo de la Escuela de París, hace en ocasión del suicidio de Gilles Deleuze: "Foucault decía en su célebre historia de la locura que la locura empieza con la vejez del mundo y que cada rostro que la locura adopta en el curso del tiempo habla de las formas y de la verdad de esa corrupción. La Escuela de París a la que me refiero y de la que Deleuze fue uno de sus más genuinos representantes estuvo profundamente marcada por la locura y representaba la vejez de nuestro mun- 
PRESENTACIÓN

do; por eso fue una Escuela que exploró la forma y la verdad de nuestra corrupción." A continuación se refiere Marti al suicidio de Guy Debord y a la muerte de Barthes, quien muere en un hospital por falta de defensas: "'él que era un buen gastrónomo se dedicaba en sus últimos tiempos a comer pan untado de excremento (...) y no deja de ser curioso que al final de sus Fragmentos de un discurso amoroso aseguraba que la verdad es lo que suprimido no deja ya al descubierto sino la muerte pues la vida no vale la pena de ser vivida"."

Después Octavi Marti describe la muerte de Nikos Poulantzas quien "se arroja desde el piso veintidós de la torre de Montparnasse tras haberse convertido en hombre de ninguna parte, solo, sin amigos, sin alumnos"; y por si fuera poco no mucho después muere Althusser luego de haber estrangulado a su mujer en su departamento de la Escuela Normal Superior.

Y como si se tratara de un vendaval de muerte abatiéndose sobre una misma escuela, tres años después muere Foucault víctima del Sida. "Ahora llega el último de los despeñados que ha elegido el suicidio por precipitación al vacío que implica tocar brutalmente la tierra estrellándose contra ella." ¿Por qué?, se pregunta este discípulo de la Escuela de París, que vio a varios de sus maestros caer en la locura, en la desesperación y en el suicidio. Y contesta: "seguro que hay muchas razones, pero ahora no me importan. Lo único que ahora me importa es la sospecha de que el drama vivido por la Escuela de París pertenece en realidad al porvenir ... de nuestra cultura claustrofóbica y $\sin$ ventanas".

Pero afortunadamente la perplejidad no se resuelve por necesidad en la desesperación; puede, debería resolverse en construcciones imaginativas o en utopías. La única manera de evitar el lanzamiento al vacío que implica tocar brutalmente la tierra estrellándose contra ella es la atracción de los grandes bienes de las grandes verdades de los grandes amores, sin los cuales, como decía Deleuze, la vida no vale la pena de ser vivida; y ése es el significado preciso de la utopía.

Utopía no significa lo irrealizable, ni siquiera la aspiración ideal. Utopía es denuncia y anuncio; denuncia de lo condenable y anuncio de 
lo deseable. El problema es que en la actualidad lo deseable lo que debe ser hecho resulta utópico, es decir, casi ideal, casi imposible; aunque, por otra parte, en los últimos diez años de nuestro siglo se puede decir que las utopías más atrevidas han tenido su cumplimiento. Utopía es un sueño de liberación, es la construcción atrevida de la esperanza. La utopía no se construye con certezas, su edificación no se sustenta en el dogmatismo profético. La utopía germina con frescura y casi ciego atrevimiento allí donde el espacio de la vida humana queda tan estrecho que necesita ser ampliado, imaginado, creado ...sueño que quiere recrear la realidad.

Donde todo está dicho por el dogma acabado y dominante y donde el proceso pedagógico consiste en la sistemática repetición, allí no hay lugar para la utopía. Sin embargo el lugar ideal para la utopía es la Universidad, cuyo encargo esencial asignado por la sociedad sensata es pensar. Pensar radicalmente, llevar a las aulas los problemas del mundo para someterlos al laboratorio del análisis crítico, y después del juicio libre y limpio construir utopías, inventar soluciones y, por supuesto, comprometerse con ellas.

Frente a la obsesión de poder y dominación en que se ha convertido 12 la política, son necesarias utopías sobre una convivencia humana en la que las personas sean respetadas por su dignidad y puedan decidir sobre sus metas, sobre el sentido y el modo de su existencia; convivencia que haga posible la libertad entre iguales, la armonía de los diferentes.

Frente a la educación conservadora, reproductora, mercantilista y plana son necesarias utopías que promuevan la plenitud humana, clave de cualquier otra transformación. Frente al arte del absurdo y de la exaltación grotesca son necesarias utopías sobre el arte comunicador de la belleza y de la fruición que engendra la belleza.

Los trabajos de esta revista en la Conmemoración de los Cincuenta Años del I.T.A.M. presentan construcciones propositivas o utopías que inventan esperanzas para el mapa de un mundo que resulte visible, porque como dice Oscar Wilde: "un mapa del mundo que no incluya el país de la Utopía no merece siquiera la pena de echarle un vistazo". 